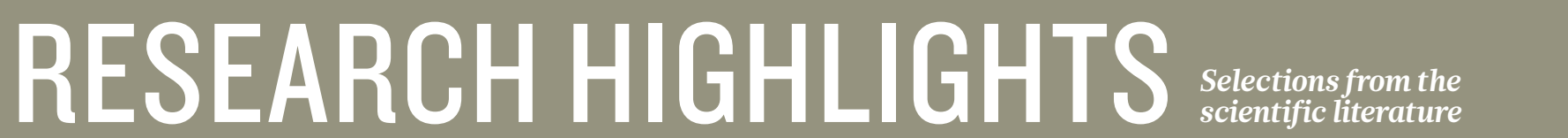

MICROBIOLOGY

\section{Bacterial version of an eyeball}

A freshwater bacterium can sense the direction of light by acting as a microscopic lens.

Spherical cyanobacteria called Synechocystis, which harvest energy from light, use protein appendages to pull themselves over wet surfaces towards light sources. A team led by Conrad Mullineaux at Queen Mary University of London found that the cells act as tiny lenses that bend and focus light. When the team illuminated one side of the cell, a bright spot appeared at the opposite end. Simulating this spot with a laser beam caused the Synechocystis cells to move away from the spot, towards the perceived source of light.

Light-sensing proteins embedded in the cellular membrane trigger the bacteria to move towards light, the researchers suggest.

eLife http://doi.org/bcgd (2016)

\section{NEUROSCIENCE}

\section{Brain circuit} for loneliness

A neural circuit at the base of mouse brains drives a loneliness-like state and motivates the animals to seek company.

Kay Tye at the Massachusetts Institute of Technology in Cambridge, Mark Ungless at the Medical Research Council's Clinical Sciences Centre in London and their colleagues found that connections between neurons in the circuit were stronger in mice that were separated from their cage mates than in those that were grouped together. Those neurons then fired more frequently when isolated mice were put in a cage with an unfamiliar mouse, compared

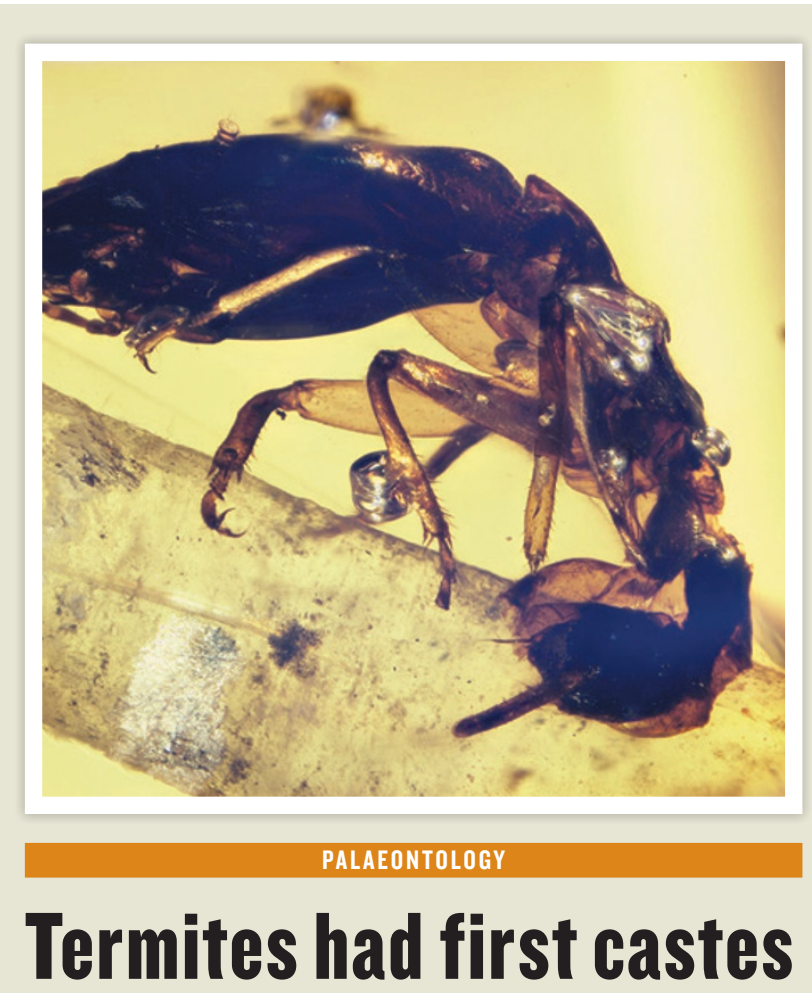

The separate castes of social insects - queens, workers and soldiers - first appeared in termites at least 100 million years ago, according to newly discovered fossils.

Although evolutionary studies have suggested that termites were first to evolve castes, there was very little fossil evidence for this. Now, Michael Engel at the University of Kansas in Lawrence, David Grimaldi at the American Museum of Natural History in New York and their colleagues report the discovery of six termite species fossilized in amber from Myanmar, which show evidence of distinct castes.

The 100-million-year-old fossils include two new species, which the authors call Krishnatermes yoddha, with queens, workers and soldiers (pictured), and Gigantotermes rex, whose 2-centimetre-long soldiers are among the largest ever reported.

Curr. Biol. http://doi.org/bch6 (2016)

with animals that had not been isolated. When the scientists inhibited the neurons with light, the isolated mice showed less interest in the stranger. Activating those neurons caused the animals to actively seek other mice.

The circuit was more responsive in socially dominant animals Cell 164, 617-631(2016)

\section{BIOENGINEERING}

\section{Exploding bubbles} kill cancer cells

A technology using tiny exploding bubbles inside tumours could one day help to mop up cancer cells during surgery.

Surgeons lack the tools to detect microtumours during cancer surgery, increasing the risk that cancer will come back. To address this, Dmitri Lapotko, now at the medicaltechnology firm Masimo in Irvine, California, and his colleagues injected gold nanoparticles into tumourbearing mice before surgery. The particles, which have cancer-specific antibodies on their surfaces, were taken up by cancer cells. After removing the main tumour, the researchers heated up the nanoparticles using a short laser pulse, causing nanobubbles to form and explode only in the cancer cells, destroying them without harming normal tissue. The explosions generated a detectable acoustic signal.

The team spotted small numbers of these cells during surgery that would otherwise have gone unnoticed. After the surgery, no tumours regrew in any animals in which residual cancer was removed, whereas more than $80 \%$ of the mice that had standard surgery died of recurring tumours.

Nature Nanotech. http://dx.doi. org/10.1038/nnano.2015.343 (2016)

\section{MATERIALS}

\section{Power from water and graphene}

Chemists have generated electricity from water by passing it through a material containing atom-thick sheets of carbon.

Liangti Qu at the Beijing Institute of Technology and his colleagues developed a $3 \mathrm{D}$ structure made from graphene oxide that had holes big enough to let moisture pass through them freely. The water molecules reacted with oxygencontaining groups in the graphene oxide, dissociating to form hydrogen ions. The oxygen groups were distributed unevenly in the material, with more at the bottom than the 